\title{
Modeling of strategies for the development of the resort-recreation sphere of Ukraine
}

\author{
Pavel Zakharchenko ${ }^{1, *}$, Ganna Kostenko ${ }^{1, * *}$, Tatyana Kungurtseva-Mashchenko ${ }^{1, * * *}$, Svitlana Zhvanenko ${ }^{1, * * * *}$, and Vik- \\ tor Mukhin ${ }^{1, \dagger}$ \\ ${ }^{1}$ Department of Economics, Entrepreneurship and Finance, Berdyansk State Pedagogical University, 4 Schmidta Str., Berdyansk, \\ 71100, Ukraine
}

\begin{abstract}
In modern world economy resort recreations - one of the most high-profitable industries of managing. Ukraine owns the powerful resort and recreational potential, effective development of which can bring a real economic benefit. For this purpose, it is necessary to form a system concept for the development of such industry, which are integral part of the economic transformations. The purpose of the article consists in development of approach to modeling of transformations strategy development of resort-recreation systems in which transformation acts as their internal and necessary part. As a result of research, the concept of transformation strategy development was grounded, as a certain period of cyclic dynamics, and the scenarios of origin of catastrophe, development and introduction of innovations is got. The offered approach assumes opportunity to consider development of economy of resort-recreation systems as process of transformation change of strategies. On this basis the model based on theory of catastrophes, which allows carrying out the scenario description of transformation strategies of resort-recreation systems is constructed.
\end{abstract}

\section{Introduction}

Recreation and tourism is one of the most profitable area of the modern world economy. For many countries, it has become not only a constantly growing source of financial income, but also due to the attraction of millions of tourists, the infrastructure of these areas is beginning to develop more actively and new additional jobs are creating. Ukraine has a strong resort and recreational potential, the effective development of which can bring real economic benefits. Therefore, the recreation industry in the process of market transformation of the economy should take one of the leading places in the structure of the economic complex of the country $[1,2]$.

However, despite the rich recreational and tourism resources base and a wide network of tourism entities [3], there is still lack of a clear modern strategy for the development of resorts that meets global and European standards in Ukraine. As a rule, the functional strategies and development plans of resort and recreational complexes are of local character and are focused mostly on the industry of rest and, and only then on the rehabilitation and curative forms of travel. As a result, the level of development of the recreation industry in Ukraine is one of the last in Europe, and the degree of compliance of its resort sector with environmental requirements for the environment and cultural and historical heritage is quite low.

\footnotetext{
*e-mail: pvzz1957@gmail.com

**e-mail: annkosten@rambler.ru

***e-mail: tanyakungurtseva2704@gmail.com

****e-mail: zhvanenko_sveta@ukr.net

†e-mail: mukhinviktors@gmail.com
}

Decreased real incomes, weakened coordination of the industry, as well as lack of control over the use of natural healing resources have led to a number of negative results including a reduction in the number of visitors by more than $50 \%$, a significant reduction in bed capacity, high prices for resort and recreational products. The result was a difficult socio-economic situation of national resorts, which for many years chosen the strategy of survival as the main direction of its development. Therefore, one of the current areas of research in this field is the development of models of strategies for socio-economic development of resorts based on modern market requirements [4, 5]. Thus, the identification of determinants and modern mechanisms of sustainable strategic development based on economic transformations is becoming increasingly apparent and important.

The concept of transformation of economic systems has deep grounds in the general economic theory. It is directly related to the problems of formation, development, change of strategies of economic systems, which have been studied in the works of many economists over a long period of time. In the process of studying of the economic transformation of resort and recreational systems [6], the authors relied on the theoretical developments contained in the works of J. Stiglitz [7], J. Shumpeter [8] and other scientists. The works [9-11] are devoted to the general problems of transition processes in the economies of different countries, as well as to the problem of transformational economy.

At the same time, many aspects of the transformation of economic systems are still insufficiently studied. In par- 
ticular, significant acceleration and complication of world economic processes, strengthening of intersystem integrations intensify transformational changes in resort and recreational systems, which requires their careful study. To date, the process of strategy transformation, taking into account its complexity and uncertainty of future stages of development, has not been fully disclosed. And a holistic concept of transformation of resort and recreational systems, which would be based on a clear understanding of its parameters and their organic relationship in a single holistic system, has not yet been developed.

\section{Methodological aspect of a research of strategies for the development of the resort-recreation sphere}

Modern trends in the development of resort and recreational systems require a systematic approach to understanding their essence, which consists in the processes of creation, operation, interaction and transformation of various systems, subjected to a single purpose of operation resort and recreational activities. This approach involves a fundamental change in development strategy. A change in strategy is an inevitable reaction to adaptation to dynamically changing environmental influences. It entails structural changes aimed at modifying resort and recreational products, optimizing the business model and transforming the development mechanism [12, 13].

Trends in systemic transformations, economic crises, dissipative phenomena, increased risks are accompanied by changes in strategies for the operation of resort and recreational systems. The basis for such changes is the transformations of economic processes inherent in the resort and recreational economy. Thus, there is a need to develop tools for analysis and practical application of transformational strategies for the development of resort and recreational systems.

The purpose of the study is to develop and analyse a model of transformation of strategies for the development of resort and recreational system based on the theory of disasters. Taking into account the results of modelling in practice allows to ensure the viability of resort and recreational systems in a dynamically changing environment and market transformations, and also shifts the emphasis from the priority of analysis and adaptation to the priority of "constructing" their own development strategies.

A vast variety of approaches to determining an effective strategy for the development of resort and recreational systems is associated with the specifics of the formation of the national economic model, which is characterized by historical traditions and professional experience in using strategic tools to achieve goals. Accordingly, the transformation strategy of resort and recreational systems will be understood as consistent management action, which is produced and is subjected to constant adjustment as a result of environmental uncertainty, and which leads to sustainable qualitative changes in the resort and recreational system in the long run by creating and strengthening competitive advantages. This definition of strategy practically means the priority of treatment and rehabilitation activities in broad integration with tourism industry. This allows us to move to a methodology focused on meeting the demand of both individual consumers and the general population by creating popular competitive offers and increasing sales, which, accordingly, leads to a significant increase in profits of resort and recreational systems [14].

It should be noted that the national economy is currently in the process of transformation, i.e. in the process of transition from one socio-economic state to a qualitatively different state. Such economic transformation has a number of specific characteristics and effects that distinguish it from economies that are relatively stationary and develop on their own basis, through self-improvement and partial changes in its inherent states, relationships and relations. Such changes are based on the modern concept of smart and sustainable growth, which was formed after the crisis of 2008 and was reflected in the report of the UN Conference on Trade and Development on world investment and investment policy of the new generation [15].

At the core of the problems of transformation of the national economy and, accordingly, the resort and recreational sphere, are issues related to the change of existing technologies, standards of functioning and the established economic order, in order to ensure economic development. Thus, when choosing a strategy, the resort and recreational system actually sets its trajectory of economic transformations to achieve economic development. But it should also be understood that the strategies that now operate successfully in foreign resort and recreation companies will not necessarily also work effectively in the national environment. Therefore, each resort and recreational system must develop and implement its own economic transformation strategy, which combines elements of different approaches to economic development [16].

Today, many economists explicitly or implicitly use the synergetic paradigm in their researches. According to its principles, the resort and recreational system is considered as an open financial and economic structure. Its development is based on the nonlinear laws and is subject to the general evolutionary laws of complex nonequilibrium systems. External disturbances and risk phenomena that accompany the development and implementation of development strategies can create situations of dynamic uncertainty and can lead to instability of the market position of such systems due to unpredictability of consumer behaviour and the complex impact of other external and internal factors. The combination of instability and risks of transformational development with the instability of the external environment, due to the dynamic nature of economic evolution and transformational cyclicality, necessitate the development of models for forecasting possible scenarios for the development of resort and recreational systems.

Intensive research on the dynamics of socio-economic systems is currently associated with the theory of economic dynamics - an actively developing area of modern economic analysis. Methods of qualitative study of dynamical systems, which constitute the content of the theory of catastrophes and chaos, are an effective tool for ob- 


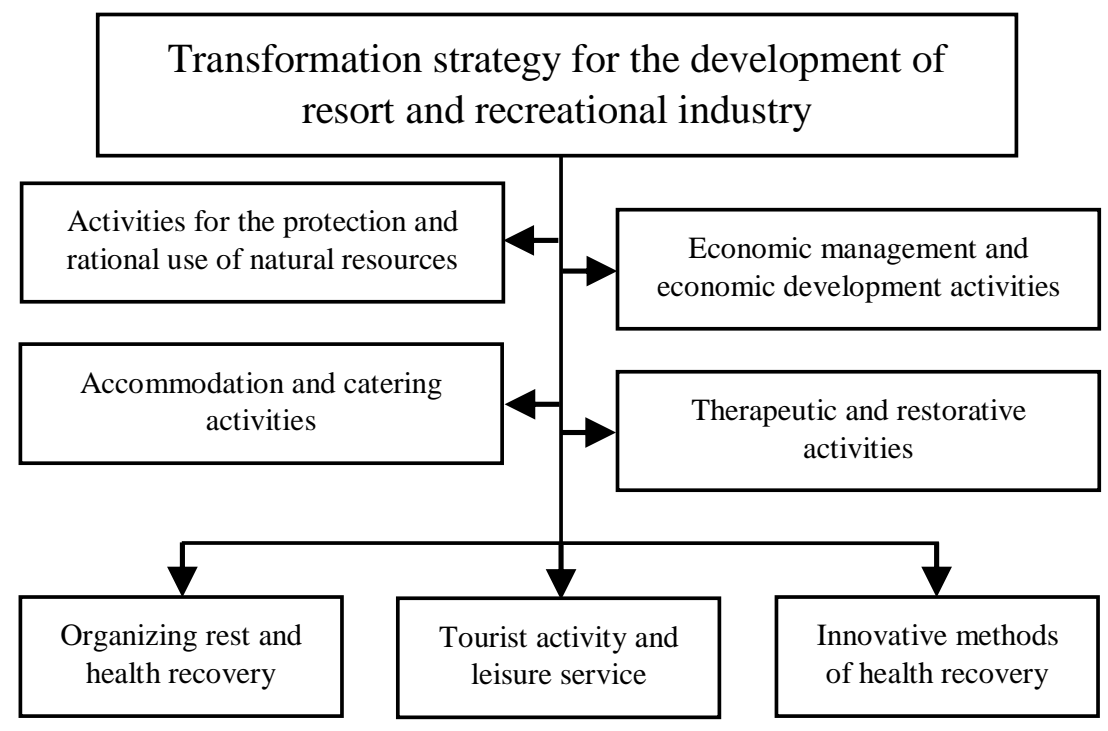

Figure 1. The structure of the transformation strategy of the resort and recreational system

taining information about the processes occurring in the simulated real systems. The use of this methodology allows us to conduct a fairly complete analysis of the dynamics of the market position of economic systems as a result of the transition to a new development strategy [17].

\section{Modeling of strategies for the development of the resort and recreational industry}

We will use the methods of catastrophe theory to model the transformation of strategies for the development of resort and recreational systems. Catastrophes are abrupt changes that occur in the form of the system's response to a gradual change in external conditions. Catastrophe theory studies sudden abrupt qualitative changes in the states of dynamical systems as a result of slow, smooth and small changes in parameters. Its approaches are essentially a methodology for modelling the transformations of evolving processes, allowing to describe the diversity of gaps from a mathematical point of view and to obtain generalizations of these phenomena. Catastrophe theory methods can be used to qualitatively characterize different types of economic dynamics by identifying structures that reflect both slow changes and the emergence of features in dynamical systems described by smooth functions with a limited number of parameters for any number of variables [18].

Consider the situation when the resort and recreational industry, which operates within the old strategy and, accordingly, produces the old resort and recreational product, is transformed according to a new development strategy and begins to produce a new resort and recreational product. Investments to expand the production of a new product will be received at the expense of the costs of modernizing the old resort and recreational product. The mathematical model of the resort and recreational system, working under the old strategy and producing only the old product, can be represented as:

$$
K \frac{\mathrm{d} y}{\mathrm{~d} t}=-y^{3}+\alpha_{1} y+\alpha_{2}
$$

where $K$ - coefficient of proportionality; $y$ - a volume of output of the old resort and recreational product during pe$\operatorname{riod} t ; \frac{\mathrm{d} y}{\mathrm{~d} t}-$ the rate of change of a volume of output of the old resort and recreational product with the respect to time $t ; \alpha_{1}$ - parameter that specifies the cost (investment) to expand the output of the old product; $\alpha_{2}=p-q$, where $p-$ the sale price of the old resort and recreational product, $q-$ costs for the development of a new resort and recreational product.

Due to the implementation of economic transformations, the resort and recreational industry is moving to a new development strategy and a new resort and recreation product is beginning to produce. The mathematical model of the resort and recreational industry, working under a new strategy and producing a new type of product, can be represented as:

$$
K \frac{\mathrm{d} x}{\mathrm{~d} t}=-x^{3}+\alpha_{3} x+\alpha_{4}
$$

where $x$ - a volume of output of the new resort and recreational product during period $t ; \frac{\mathrm{d} x}{\mathrm{~d} t}-$ the rate of change of a volume of output of the new resort and recreational product with the respect to time $t ; \alpha_{3}-$ parameter that specifies the cost (investment) to expand the output of the new product; $\alpha_{4}=p_{n}$, where $p_{n}$ - the sale price of the new resort and recreational product.

Since the costs $q$ go to expanding the production volume of a new product, we will assume that $\alpha_{3}=q$. Then the system of equations describing the functioning of the resort and recreational industry when producing the old and new product, will look like:

$$
\begin{aligned}
& K \frac{\mathrm{d} y}{\mathrm{~d} t}=-y^{3}+\alpha_{1} y+(p-q) \\
& K \frac{\mathrm{d} x}{\mathrm{~d} t}=-x^{3}+q x+p_{n}
\end{aligned}
$$


Assume that the costs $q$ begin to be incurred at some point of time $t_{i}$ in the operation of the resort and recreational industry and continue over time $\Delta t$ according to the law $q=u t$, where $u-$ the rate of change of investment in the release of a new resort and recreational product. Then, varying the price of the old resort and recreational product $p$, the price of a new product $p_{n}$, investment to expand the production of the old product $\alpha_{1}$, time when investing in the release of a new product starts $t_{i}$, their duration $\Delta t$ and speed $u$, you can get different scenarios of working of the resort and recreation industry.

\section{Simulation results}

Consider the main scenarios obtained as a result of modeling the transformation of the strategy of development of the resort and recreational system at different values of the parameters.

Scenario 1. The evolution of the economy of the resort and recreational industry, operating within the old development strategy.

One of the scenarios obtained in modeling the strategy of development of the resort and recreational industry was the scenario corresponding to the situation when the system continues to operate under the old development strategy (figure 2).

As can be seen from figure 2 the economy of the resort and recreational industry, which operates under the old strategy is developing rapidly in the early stages, and this corresponds to the life cycle of resort destinations. The growth of profits and production of the old resort and recreational product in the leisure industry is facilitated by stable demand and low prices $(p=3)$. However, since time $(t=4.8)$ growth has slowed significantly, investment in the old product is significantly reduced $\left(\alpha_{1}=3\right)$.

Since time $(t=6)$, there is a sharp drop in profits of the resort and recreational industry, which leads to the transformation of development strategy and the beginning of the release of a new product. Due to the low rate of investment $(u=2.25)$, late transformation $\left(t_{i}=6\right)$, low prices for the new product and a sharp drop in profits to zero by the time $(t=8)$ resort and recreation system is in disaster.

Scenario 2. Transformational growth of the economy of the resort and recreational industry, operating under the new development strategy.

Another scenario obtained in modeling the strategy of development of the resort and recreational industry was the scenario corresponding to the situation of completion of economic transformations and transition to a new strategy (figure 3).

The scenario presented in figure 3, confirms the concept of the need to move to a transformational development strategy. In the context of such a strategy, there is a post-transformational increase in profits $\left(t_{i}=8\right)$, which corresponds to the course of the transformation cycle and the growth of market confidence. The resort and recreational system goes from the point of catastroph. The growth of demand and the release of a new resort and recreational product of a therapeutic and restorative nature is facilitated by the growth of demand and price in- crease $\left(p_{n}=4\right)$. This reduces investment in the old product $\left(\alpha_{1}=2\right)$ and increases the rate of investment in the new product $(u=4.3)$. It should be noted that the economic strategy for managing the development of the resort and recreational industry should include the growth of the prices of the providing services through the implementation of the additional benefits for consumers, as well as the improving service quality.

Scenario 3. Shifting the transformation of the strategy of development of the resort and recreational system in time.

Under the conditions of the transformation cycle, earlier transformations are considered as a way to mitigate the effects of the crisis [19]. To simulate such a scenario, we reduce the time parameters of the model. In figure 4 presents a scenario of early transformation of the strategy of development of the resort and recreational system $\left(t_{i}=3\right)$.

The scenario presented in figure 4, demonstrates a situation when the early start of the transformation of the strategy of development of the resort and recreational industry contributes to the growth of market confidence, which, accordingly, leads to earlier and much greater investment in innovation. The resort and recreation system starts from the point of catastrophe, but the average level of profit decreases. This scenario can be called a "reversal strategy", i.e. if it is known that a catastrophe will occur, the transformation should be carried out at an early stage. In this case, the early start of investment will be made by reducing the average level of profit.

Scenario 4. Reducing the speed of investment in the transformation of the strategy of development of the resort and recreational industry.

Another scenario obtained in modelling the transformation of the strategy of development of the resort and recreational industry was the scenario corresponding to the situation of "overheating of the resort and recreational economy" (figure 5).

This scenario reflects the decline of the rate of investments from to. The resort and recreation industry starts from the point of catastrophe, but the level of profit decreases sharply. Scenario analysis shows that there is some critical rate of investment, above which the resort and recreational industry suffers a catastrophe, i.e. overheats. A similar situation is observed with the investment interval: the smaller the investment interval at a constant speed, the higher the probability of a catastrophe, i.e. it is necessary to increase investment, but for a longer time interval.

\section{Conclusions}

Analysis of the current state and trends of the world and domestic economy led to the conclusion that the resort and recreational sphere is one of the most profitable and most dynamically developing, which is one of the main sources of revenue for a government budgets of many developed countries. However, the available resource potential of domestic resort and recreational systems is insufficiently 


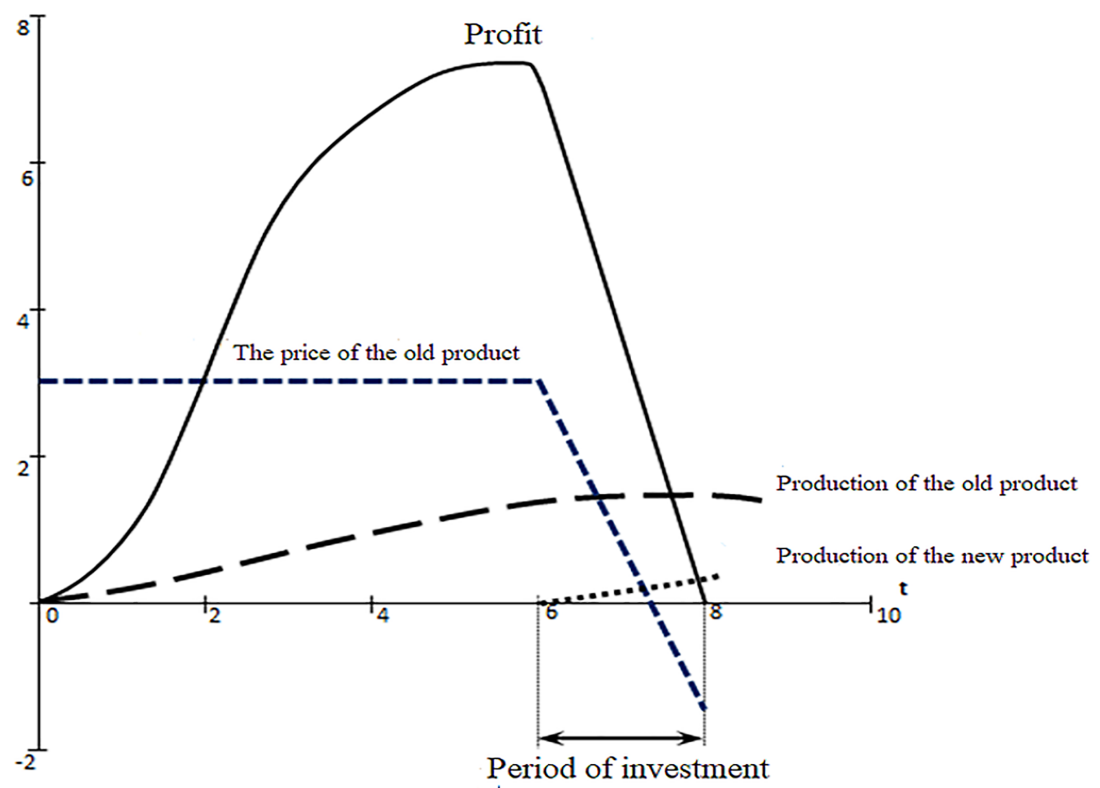

Figure 2. The scenario of a catastrophe in the economy of the resort and recreational system at $\alpha_{1}=3, p=3, p_{n}=2, t_{i}=6, \Delta t=2$, $u=2.25$

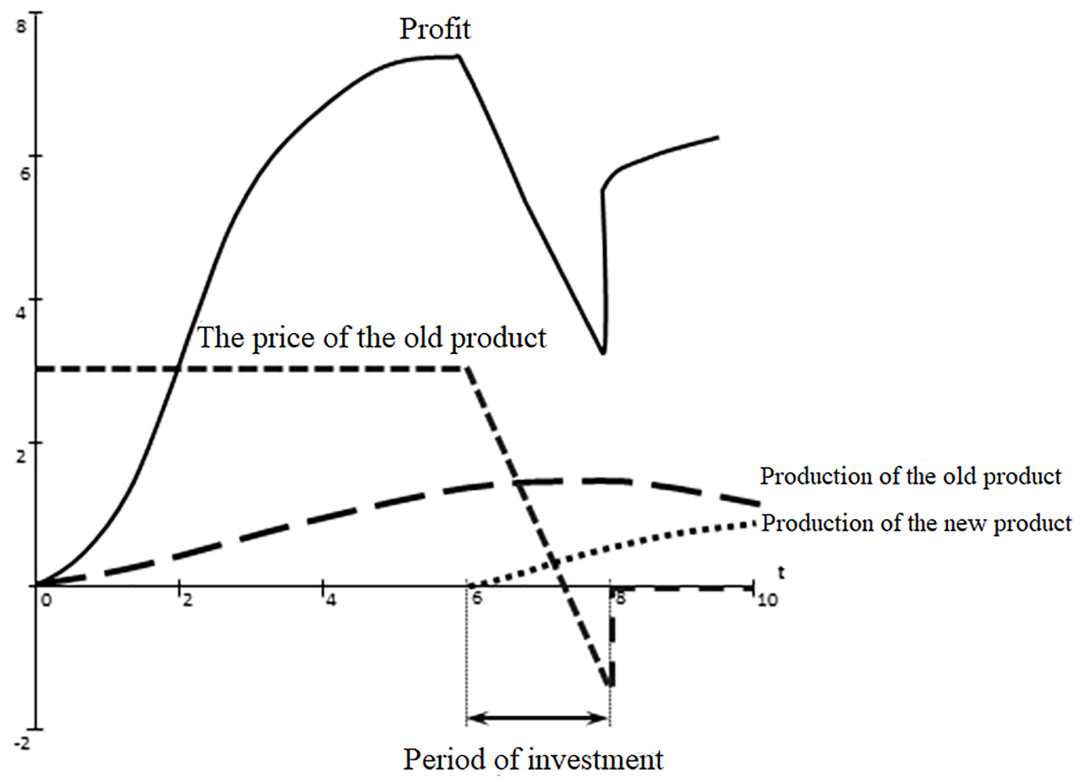

Figure 3. The scenario of economic growth of the resort and recreational system at $\alpha_{1}=2, p=3, p_{n}=4, t_{i}=6, \Delta t=2, u=4.3$

used, and the state and effectiveness of recreational development not only lags far behind the leading countries of the world, but also does not meet the needs of modern consumers.

The conducted study on the development of economic mechanisms and models for the effective development of the resort and recreational sphere has identified a set of basic modern approaches and methodologies for managing the development of resort and recreational systems. Their systematization proves that there is some unique predominant characteristic that acts as a key parameter, a factor that determines the level of development of the system. At the same time, there is no systematic approach to this is- sue, which makes it impossible to reproduce sustainable competitive advantages, form a set of modern competitive strategies and create tools for choosing economic action in multi-alternative situations caused by high and uncertain external and internal environment. In order to eliminate the existing discrepancies, we have used a model approach to the creation of a mechanism for the transformation of strategies for the development of organizations of the resort and recreational complex based on the theory of disasters.

Analysis of the results of modelling the transformation of strategies for the development of resort and recreational system at different values of the parameters allows 


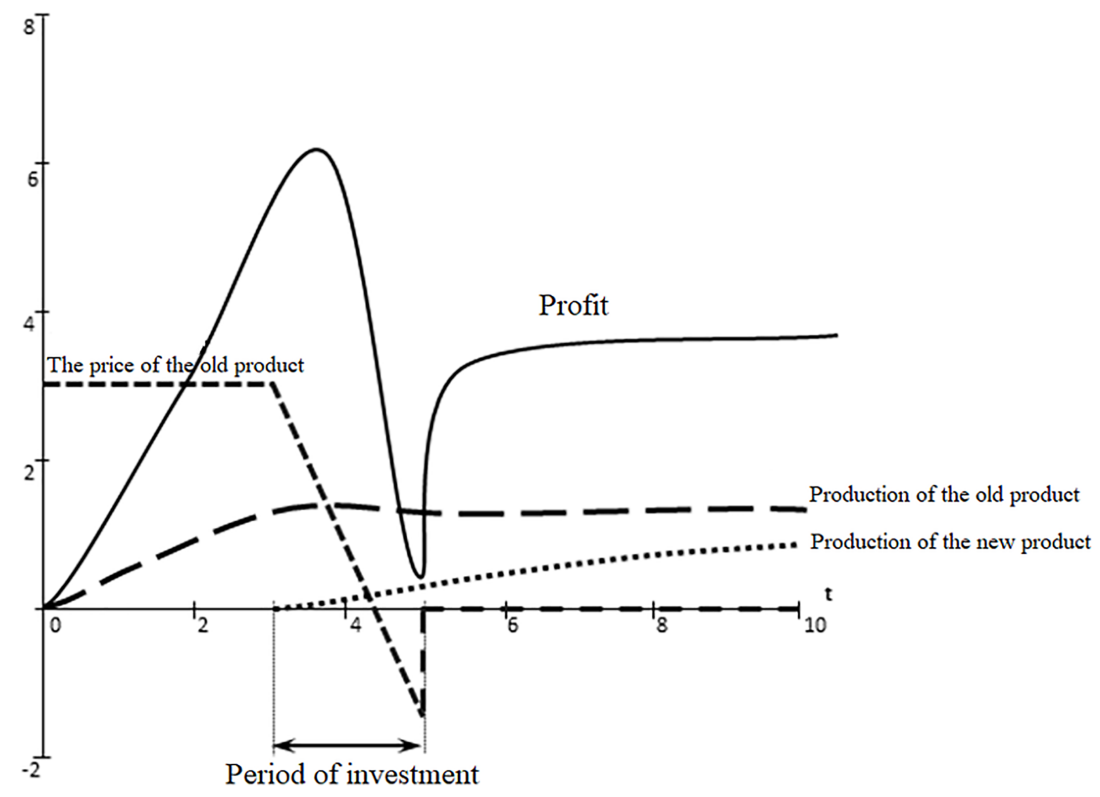

Figure 4. The scenario of shift in time of transformation of strategy of development of resort and recreational system at $\alpha_{1}=3, p=3$, $p_{n}=4, t_{i}=3, \Delta t=2, u=2.25$

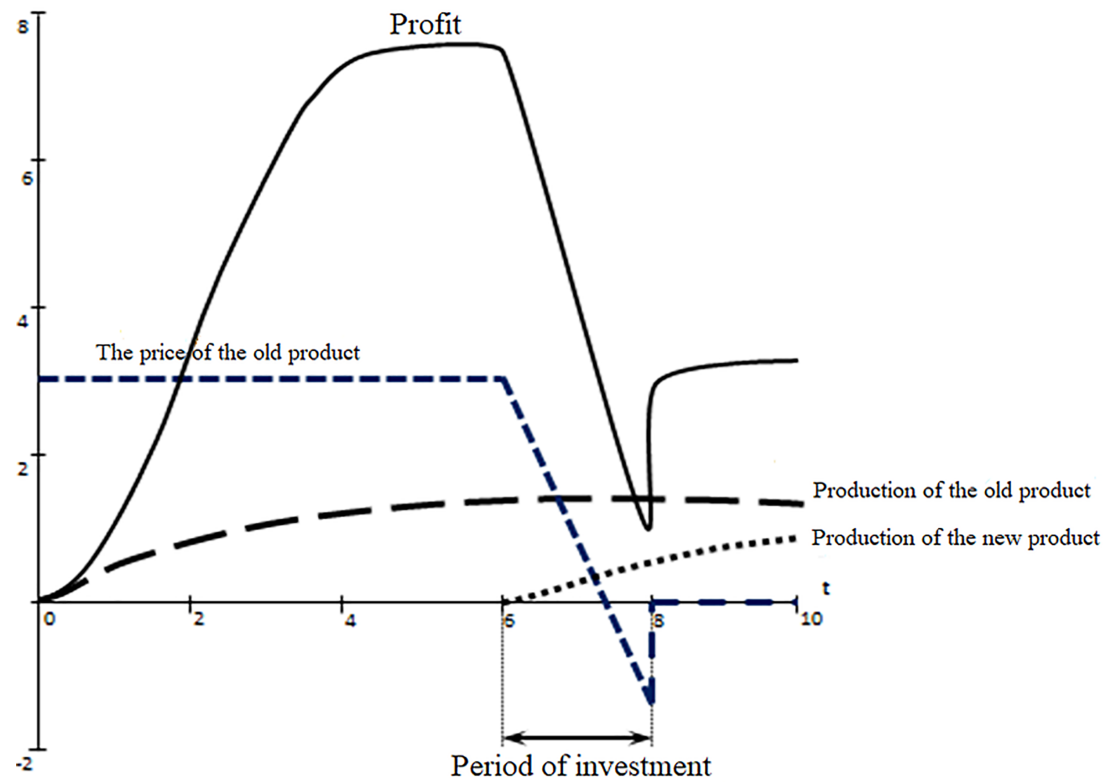

Figure 5. The scenario of reducing the rate of investment at $\alpha_{1}=3, p=3, p_{n}=4, t_{i}=6, \Delta t=2, u=2$

us to conclude that transformational changes are one of the most important prerequisites to reaching sustainable economic development and, consequently, effective functioning of resort and recreational economy as a whole. The generalization of the results of model experiments in the presence of several strategies for the development of the resort and recreational system allowed to obtain quantitative and qualitative values of factors, to explore the trajectories of movement depending on the impact of economic transformation.

The transformation of strategies should correspond to the second scenario of the model, i.e. the transformational growth of the economy of the resort and recreational sys- tem, which operates within the new development strategy. In this case, there is a significant increase in profits of the resort and recreational system and an increase in demand for resort and recreational products.

\section{References}

[1] G.M. Romanova, Strategicheskoe planirovanie razvitija kurortov $i$ turizma $v$ regione (SPbGUEF, Saint Petersburg, 2018)

[2] M. Bokov, Strategic management of recreational enterprises in conditions of transitional economy (National Institute for Strategic Studies, Kyiv, 2011) 
[3] O. Hanchuk, O. Bondarenko, I. Varfolomyeyeva, O. Pakhomova, T. Lohvynenko, E3S Web of Conferences 166, 09005 (2020)

[4] E.A. Makarycheva, Ekologija i zhizn 4, 19 (2017)

[5] M. Amirkhanov, A. Tatarinov, Economic problems of development of recreation regions (Helios, Kyiv, 2017)

[6] P. Zakharchenko, A. Kostenko, T. KungurtsevaMashchenko, I. Gorbachova, CEUR Workshop Proceedings 2422, 5 (2019)

[7] J.E. Stiglitz, People, Power, and Profits: Progressive Capitalism for an Age of Discontent (W. W. Norton and Company, New York, NY, 2019)

[8] J.A. Shumpeter, The Theory of Economic Development: An Inquiry Into Profits, Capital, Credit, Interest, and the Business Cycle. Transl. by Redvers Opie (Oxford University Press, 1961)

[9] V. Heiets, Transformatsiini peretvorennia. Ekonomika Ukrainy: stratehiia $i$ polityka dovhostrokovoho rozvytku (Feniks, Kyiv, 2013)

[10] W. Strang, Recreation and the Local Economy; an Input-output Model of a Recreation-oriented Econ- omy, Technical report (University of Wisconsin Sea Grant Program, 1970)

[11] O. Kovtun, A. Opalenko, O. Ivanylova, CEUR Workshop Proceedings 2422, 27 (2019)

[12] G.B. Klejner, Vestnik RAN 9, 41 (2018)

[13] A.A. Thompson, A.J. Strickland, Strategic management: Concepts and cases (McGraw-Hill/Irwin, 1992)

[14] A.T. Bykov, Kurortno-turistskij kompleks kak obekt upravlenija (SPbGUEF, Saint Petersburg, 2017)

[15] R. Nuree, Voprosy jekonomiki 9, 136 (2018)

[16] E. Inskeep, National and regional tourism planning: methodologies and case studies (Routledge, London, 1994)

[17] R.E. Lucas, T.J. Sargent, Rational expectations and econometric practice, Vol. 2 (U of Minnesota Press, 1981)

[18] W. Sanns, Catastrophe theory with Mathematica: A geometric approach (Der Andere Verlag, 2000)

[19] G.G. Malinetsky, Mathematical Foundations of Synergetics: Chaos, structures, computational experiment (LIBROKOM, Moscow, 2012) 